\title{
Management of Febrile Neutropenia in Patients receiving Chemotherapy for Solid Tumors: A Retrospective Study of Twenty Cases from the Radiotherapy Centre, Accra, Ghana
}

\author{
Gestion des neutropénies fébriles chez les patients recevant une chimiothérapie pour les tumeurs \\ solides: une étude rétrospective de vingt cas du Centre de Radiothérapie, Accra, Ghana
}

\author{
V. Vanderpuye, J. Yarney, K. Beecham
}

\begin{abstract}
BACKGROUND: One in ten patients on anticancer medication will develop febrile neutropenia irrespective of tumour type. There is need to protect our patients from this fatal condition while optimising chemotherapy. This may be difficult for a poor country. OBJECTIVE: To assess the management of cancer patients with febrile neutropenia in a low resource setting.

METHODS: Records of 20 cancer patients with febrile neutropenia $(F N)$ over a three-year period were retrospectively analysed. Data retrieved included age, sex, type of cancer and number of cycles of chemotherapy taken. Other parameters included initial temperature, site of infection, absolute neutrophil count (ANC) at presentation and antibiotic choice. Use of antifungal drugs, duration of fever and overall treatment outcome were also assessed. RESULTS: The male : female ratio was 3:2 with a median age of 24 years (range: 15 - 68 years), and a mean temperature of $38.8{ }^{\circ} \mathrm{C}$ (range $38.0-39.8{ }^{\circ} \mathrm{C}$ ). Mean absolute neutrophil count was $0.2 \times 10^{9}$ (range: 0.0 to $0.6 \times 10^{9}$ ). Thirteen $(65 \%)$ received Cisplatin, five (25\%) received Adriamycin, two (10\%) received Paclitaxel or Cyclophosphomide-Methotrexate-5, Fluorouracil (CMF). Ten $(50 \%)$ developed FN with the first cycle of chemotherapy, and $\operatorname{six}(30 \%)$ in the second cycle. Twelve $(60 \%)$ had oral infection, four $(20 \%)$ had gastroenteritis and single episodes of respiratory and urinary tract infections. Eleven $(55 \%)$, received Ceftriaxone and Gentamycin, five $(25 \%)$ cases received Levofloxacin or ciprofloxacin and Amoxicillin/clavunate \pm metronidazole; two cases(10\%), Ceftazidime and Gentamycin; two cases $(10 \%)$ received Meropenem. Twelve $(60 \%)$ patients had antifungal therapy for oral candidiassis. Eight $(40 \%)$ patients received growth factors. The mean fever duration was 4.5 days (range 1-10 days). Two (10\%) of the patients died.

CONCLUSION: Febrile neutropenia in resource limited countries can be managed with good history and physical examination skills. Aminoglycosides are important components of empiric treatment in Ghana. WAJM 2010; 29(5): 303-308.
\end{abstract}

Keywords: Febrile Neutropenia, Empiric, Antimicrobial, Antifungal, Chemotherapy

\section{RÉSUMÉ}

CONTEXTE: Un patient sur dix sur les médicaments anticancéreux se développer une neutropénie fébrile, indépendamment du type de tumeur. Il est nécessaire de protéger nos patients de cette maladie mortelle, tout en optimisant la chimiothérapie. Cela peut être difficile pour un pays pauvre.

OBJECTIF: Pour évaluer la gestion des patients cancéreux présentant une neutropénie fébrile dans un contexte de faibles ressources.

METHODES: Les dossiers de 20 patients atteints de cancer avec neutro-Pénia fébrile $(F N)$ sur une période de trois ans ont été analysés rétrospectivement. Les données extraites sont l'âge, le sexe, le type de cancer et le nombre de cycles de chimiothérapie prises. D'autres paramètres inclus température initiale, site de l'infection, nombre absolu de neutrophiles (ANC) lors de la présentation et le choix antibiotique. L'utilisation de médicaments antifongiques, durée de la fièvre et le résultat global de traitement ont également été évaluées. RÉSULTATS: Le ratio hommes / femmes était de 3:2 avec un âge médian de 24 ans (extrêmes: 15 - 68 ans), et une température moyenne de 38,8 oC (38,0 à 39,8 0C gamme). Nombre moyen de neutrophiles était de 0,2 x 109 (fourchette: 0,0 à 0,6 x 109). Treize (65\%) ont reçu du cisplatine, cinq (25\%) ont reçu Adriamycine, deux (10\%) ont reçu le paclitaxel ou Cyclophosphomide-méthotrexate-5, fluoro-uracile (CMF). Dix (50\%) de la bande au point avec le premier cycle de chimiothérapie, et six (30\%) dans le deuxième cycle. Douze (60\%) avaient une infection par voie orale, quatre $(20 \%)$ ont eu une gastroentérite et d'épisodes unique d'infections respiratoires et urinaires. Onze (55\%), reçu de la ceftriaxone et Gentamycin, cinq (25\%) des cas ont reçu la lévofloxacine ou ciprofloxacine et amoxicilline / métronidazole clavunate + ; deux cas (10\%), la ceftazidime et Gentamycin; deux cas (10\%) ont reçu méropénem. Douze (60\%) patients avaient un traitement antifongique par voie orale pour candidiassis. Huit (40\%) patients ont reçu des facteurs de croissance. La durée moyenne de la fièvre était de 4,5 jours (extrêmes 1-10 jours). Deux (10\%) des patients sont décédés.

CONCLUSION: La neutropénie fébrile dans les pays aux ressources limitées peuvent être gérées avec l'histoire et de compétences examen physique. Les aminosides sont des composantes importantes du traitement empirique au Ghana. WAJM 2010; 29 (5): 303-308.

Mots-clés: neutropénie fébrile, empirique, antimicrobiennes, antifongiques, chimiothérapie. 


\section{INTRODUCTION}

Febrile neutropenia is an oncological emergency occurring in patients undergoing chemotherapy for cancer, and is associated with significant morbidity, mortality and high cost of treament. ${ }^{1}$

The febrile episode is preceded by a reduction in the absolute neutrophil count (ANC) which comprises of segments, blasts and neutrophils. Even though neutropenia is defined as ANC less than $1.0 \times 10^{9} \mathrm{~L}$ cells, this figure is referenced for Caucasians and there is a suggestion that it in blacks it should be less than $1.2 \times 10^{9} \mathrm{~L}$ cells due to mild neutropenia being a normal phenomenon. $^{2}$

Febrile neutropenia is defined as a single oral temperature of $\geq 38.3^{\circ} \mathrm{C}$ or $38^{\circ} \mathrm{C}$ for more than one hour, associated with a significant reduction in granulocyte count $\left(\mathrm{ANC} \leq 0.5 \times 10^{9} \mathrm{~L}\right.$ or $1.0 \times 10^{9} \mathrm{~L}$ cells, but predicted to fall to $<500$ cells/ $\left.\mathrm{mm}^{3}\right) .{ }^{1}$ Mortality rates have reduced from 50 percent in the 1960 s to less than 10 percent today due to improved management strategies. ${ }^{3}$ Most chemotherapy agents/protocols have the potential of causing febrile neutropenia. Most cause a blood count nadir at 10 to 14 days, but can occur anytime from a few days to about 6 weeks depending on the drug. ${ }^{1}$

The relationship between low neutrophil count and the increased risk of infection was published in 1966 by Bodey GP et al. ${ }^{4}$ They noted that the major threat of neutropenia is bacterial infection, and the greatest risk was in patients with ANC less than $0.1 \times 10^{9} \mathrm{~L}$ cells. Signs and symptoms of infection are however often subtle due to a lack of adequate inflammatory response.

In the absence of an obvious source of infection which occurs in $50 \%-70 \%$ of cases, empiric antibiotic treatment should cover Gram positive bacilli and Gram negative cocci as microbiological evidence of infection occurs in less than $15 \%$ of cases. ${ }^{1}$

Antibiotic choice however depends on the prevailing local condition such as drug availability, isolated pathogens, risk/ severity of bacterial sepsis, resistance patterns, ease of administration and cost in our environment. Earlier studies have reported a 70 percent mortality if administration of antibiotics (within five hours) is delayed. ${ }^{5}$

The use of granulocyte stimulating growth factor (G-CSF) has been repeatedly shown to be effective in prophylaxis and reducing the duration of neutropenia and hospital stay but does not affect mortality. ${ }^{3}$

Since February 2005, patients who developed febrile neutropenia in the Radiotherapy Unit of Korle-Bu Teaching Hospital were admitted and managed inhouse instead of the Surgical Medical Emergency Unit.

The purpose of this study was to assess the outcome of patients admitted and managed at the Oncology Unit in Accra, Ghana between January 2005 and February 2008. As a developing country we have many limiting resources in the health care system especially for emergency care.

\section{SUBJECTS, MATERIALS, AND METHODS}

The medical charts of 20 patients on chemotherapy admitted to the Radiotherapy Centre for febrile neutropenia from February 2005 to February 2008 were analyzed. Patients had received chemotherapy for solid tumours in the preceding days or weeks and had a temperature of $\geq 38.3^{\circ} \mathrm{C}$.

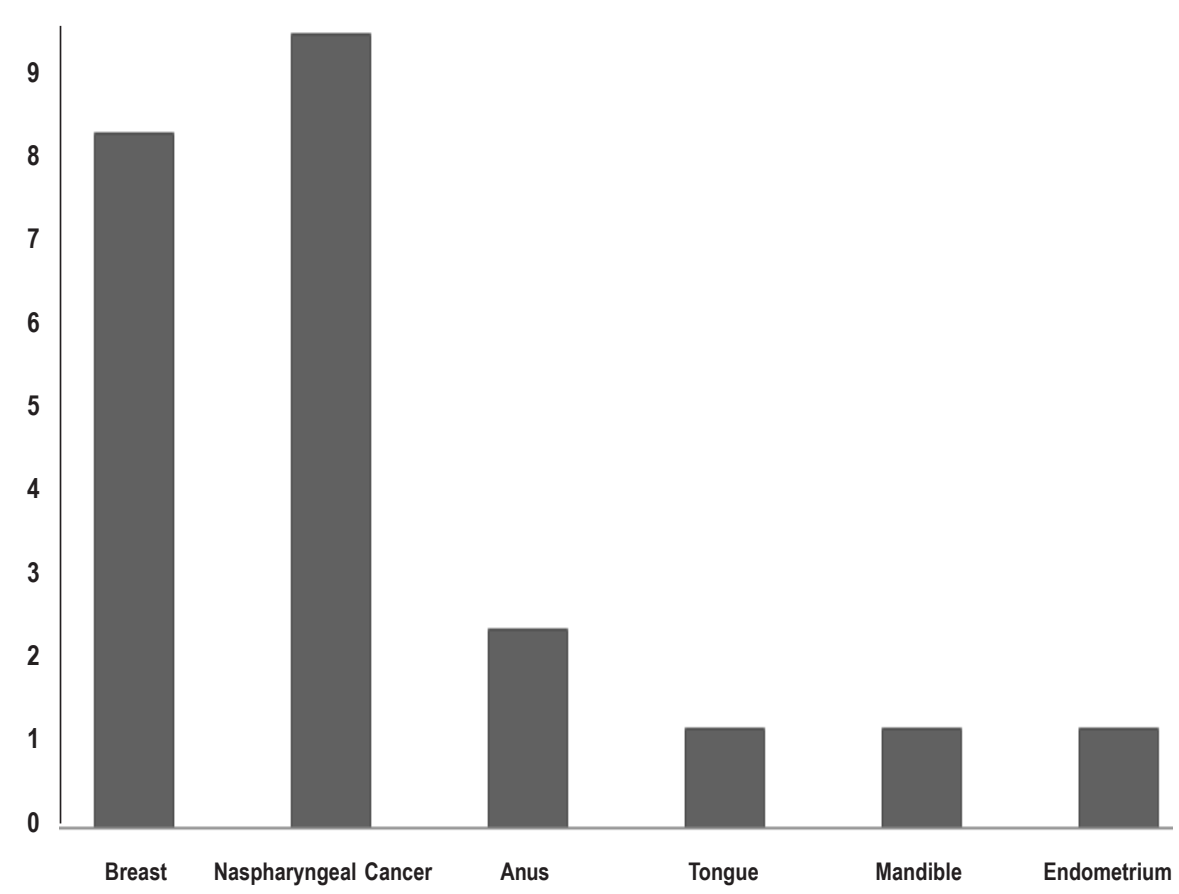

Fig. 1: Distribution of Primary Site of Cancer for 20 Neutropenia Patients
Data retrieved included age, sex, type of cancer and number of cycles of chemotherapy taken. Other parameters included initial temperature, site of infection, ANC at presentation and antibiotic choice. Use of antifungal drugs, duration of fever (defined as the number of days lapsed for complete resolution of fever for $>24$ hours) and overall treatment outcome were also assessed. This retrospective research was conducted in accordance with the Declaration of Helsinki and national and institutional standards. Averages of data are summarised as means or medians.

\section{RESULTS}

Of the 20 patients records analyzed, $12(60 \%)$ were females and $8(40 \%)$ males with a median age of 42 years. (Range 15 to 68 years), and male to female ratio 3:2. Absolute Neutrophil Count (ANC) at presentation ranged from 0 to $0.6 \times 10^{9} / \mathrm{L}$ with only one patient having a value greater than $0.5 \times 10^{9} / \mathrm{L}$.

Eleven $(52 \%)$ patients had cancers involving the head and neck region comprising nasopharyngeal cancer $(n=9)$ and one case each of tongue and mandible. Breast cancer accounted for seven $(35 \%)$ of cases and anorectal cancer accounted for two (10\%), (Fig 1.). 
With regards to chemotherapy regimens $13(65 \%)$ patients had Platinum based regimens, five (25\%) anthracycline based and 2(19\%) patients received either CMF or Taxane drugs. The chemotherapy agents were used either alone or in combination. Only the two patients with anorectal cancer received concomitant radiation.

The mean initial temperature was $38.8^{\circ} \mathrm{C}$ (Range $38^{\circ} \mathrm{C}$ to $39.8^{\circ} \mathrm{C}$ ). Oral mucosa was the most frequent site of infection, occurring in $12(60 \%)$ of the admitted patients. Four (20\%) presented with gastroenteritis and two single episodes of respiratory and urinary tract infection. In two cases, no site of infection was identified (Table 1). Seven patients who had blood and urine cultures yielded no organisms, malaria having been ruled out by blood films and test. Diagnosis was mainly by history and physical examination as laboratory analysis especially for culture and sensitivity could not be performed immediately before initiation of antibiotics. However, these were requested when there was a change in clinical situation, necessitating prompt re-evaluation and a change in antimicrobial choice.

Table 1: Initial Site of Infection for 20 Neutropenic Cancer Patients

\begin{tabular}{lc}
\hline Site of Infection & No. of Patients (\%) \\
\hline Oral Mucosa & $12(60)$ \\
Gastrointestinal & $3(15)$ \\
Upper Respiratory & $2(10)$ \\
Urinary tract & $1(5)$ \\
Unknown site & $2(10)$ \\
\hline
\end{tabular}

Eleven $(55 \%)$ patients had Cisplatin with 5-fluorouracil with seven patients developing neutropenic fever after the first cycle. Seven (35\%) patients received Anthracycline-based chemotherapy, four developed febrile neutropenia after the first cycle. The patient who received Taxane chemotherapy as well as the other who received CMF developed neutropenia after the first cycle. In total 11(55\%) developed febrile neutropenia with first cycle and 7(35\%) with second cycle. Two $(10 \%)$ developed febrile neutropenia after three or more cycles. None of the patients had prior chemotherapy. Choice of antibiotic depended on site of infection, affordability and performance status.

Eleven $(55 \%)$ patients had Ceftriaxone combined with Gentamycin; two (10\%) patients had Ceftazidime with Gentamycin. Levofloxacin with Augmentin or metronidazole was used in five $(25 \%)$ patients of patients. Three (15\%) patients received Meronem-based antibiotics, two as second line. Two patients had Ciprofloxacin and Amoxicillin/clavulinic acid. Ceftriaxone with Gentamycin was the most frequently used, with only one patient requiring change of antibiotic. Except for one patient, all who got Gentamycin upfront did not require antibiotic change. Five out of six patients who received amoxicillin/ clavulinic acid with ciprofloxacin or levofloxacin as initial therapy required a change in drug. Metronidazole was added when there was gastroenteritis. Antifungal therapy with fluconazole was given in $12(60 \%)$. In all but one there was evidence of fungal infection in oral mucosa on admission.

Eight $(40 \%)$ patients had Granulocyte Colony Stimulating Factor (G-CSF) during their neutropenic fever episode with an average of three injections per patient (range 1 to 6). Six of them received it after five days of persistent neutropenia and fever. Cost was the major deterrent in the limited use of GCSF.

The mean duration of fever was 4.5 days (Range 1 to 10 days). Patients were discharged home on oral ciprofloxacin and augumentin for ten days when afebrile for 72 hours.

Overall, 18(90\%) recovered from their neutropenic episode. Mortality from febrile neutropenia was $2(10 \%)$. The two patients who died required a change in antibiotics three consecutive times in addition to antifungal agents.

\section{DISCUSSION}

Fever in a patient with neutropenia is a grave condition requiring immediate emergency medical attention to avoid fatality. ${ }^{6}$ Several trials have indicated similar outcomes for oral versus intravenous antibiotics to cover both gram negative cocci and gram positive bacilli, however, the advantage of intravenous route cannot be overlooked in gravely ill patients. ${ }^{7}$ The increased use of multimodality treatment has increased local control and survival rates as well as increased toxicity, with most serious being febrile neutropenia secondary to anticancer drugs. ${ }^{8}$ Dose adjustments to ameliorate this side effect have been shown to be detrimental by reducing survival rates in most cancers. ${ }^{9,10}$ It seems the solution to optimize dose is by use of granulocyte stimulating growth factors which comes at a prohibitive cost to patients in developing countries.

In our institution we realized the high mortality rate when our patients were managed elsewhere in the hospital. The reason for this may be multifactorial. We therefore developed a policy to manage them in our limited inpatient department with one to one nursing care and an isolated ward.

\section{Investigations Recommended for Febrile Neutropenia}

Even though it is recommended that all neutropenic patients have immediate full blood count, renal and liver profile, wound swabs, chest X-ray and CT scans, blood, urine and sputum cultures, ${ }^{11}$ microbiology laboratory tests were however typically difficult to obtain prior to start of antibiotics as patients traditionally presented on Fridays , after hours or had limited financial resources. In spite of somewhat suboptimal conditions in developing countries, we are able to manage these cases successfully and present a retrospective study of twenty cases of febrile neutropenia patients who presented to us between 2005 and 2008 .

\section{Anticancer Drugs Causing Neutropenia}

Several studies including one from Curtin et al have noted high rate of febrile neutropenia in patients receiving cisplatin-based chemotherapy. ${ }^{12}$ In our analysis more than half of the patients $(n=13)$ received cisplatin-based chemotherapy for head and neck or anal cancer in combination with continuous infusion of 5-Fluorouracil, explaining the high incidence of oral mucositis. Anthracyclines such as Adriamycin are also associated with increased incidence of 
febrile neutropenia. ${ }^{13}$ This is consistent with our findings that breast cancer patients receiving Adriamycin made up one-third of the group. Two patients who received relatively less myelosuppressive drugs (paclitaxel, a taxane and CMF) developed neutropenia. This goes to support the saying in oncology that all anticancer drugs have the potential of causing febrile neutropenia and therefore strict monitoring of blood counts is mandatory. These two patients were actually chemotherapy-naive and may have had other risk factors not discussed here.

In relation to cycle of chemotherapy, a recent report by Crawford J. et al, ${ }^{14}$ showed that two-thirds of patients with severe neutropenia and febrile neutropenia occur in the first cycle.

This finding tallied with our results showing that majority of our febrile neutropenia cases occurred following the first cycle and another thirty percent after the second cycle (Table 1).

Nineteen $(95 \%)$ of our patients had $\mathrm{ANC} \leq 0.5 \times 10^{9} \mathrm{~L}$ and on clinical evaluation were found to be at least moderate risk and thus the use of intravenous antibiotics was justified. ${ }^{7,8}$ Moreover, $60 \%$ had oral mucositis with dysphagia, odynophagia and dehydration, precluding initial use of oral drugs.

\section{Site of Infection}

Unlike many text book descriptions of infections in these group of patients, we did not document a skin, respiratory and catheter site infections. This may be explained by the fact that none of our patients had indwelling catheters for feeding, urination or drug delivery. There was only one case of documented pneumonia and urinary tract infection. Not an uncommon finding, a few patients had no evidence of site of infection. This pattern could be different if larger number of patients and more variety of drugs are involved.

\section{Choice of Antimicrobial Agent}

Standard empiric antibiotics are recommended to cover the most probable infectious agents in febrile neutropenia, but we must remember that the spectrum of infectious agents varies across different regions of the world and amongst different institutions within the same region and tend to change over time. ${ }^{15,21}$ For us, the ideal choice of drug combination becomes more complicated by the lack of confirmation of infectious agent by laboratory test, lack of financial resources and absence of ideal environment to prevent nosocomial infectious in this very vulnerable group. Sometimes we have to resort to the combination with minimal cost but high efficiency taking into consideration the clinical state of the patient. At the time of this study period, there were no drugs to tackle suspected methicillin-resistant Staphylococcis aureus.

The most commonly recommended monotherapies include carbepenems (e.g. Imepenem/cislastin, meropenem) or extended spectrum cephalosporin's (e.g. Ceftazidime, cefipime). ${ }^{16}$ Prior to 2005 , we noted that none of our patients receiving monotherapy with carbepenems or fourth generation cephalosporin had resolution of fever. We then developed a departmental policy to treat with combination therapies only.

Recommended combination therapies include an aminoglycoside with anti-pseudomonal penicillin with or without beta lactamase inhibitor or cephalosporin with anti-pseudomonal penicillin. ${ }^{16}$ as a general policy for us, very sick patients received gentamycin (an aminoglycoside) combinations. The dose and frequency of gentamycin depended on renal function.

Patients who could not afford meropenem, ceftazidime or ceftriaxone but when clinically stable received ciprofloxacin with amoxicillin/clavulinic acid. Metronidazole was included for gastroenteritis or where indicated. Other combinations were also given based on site of infection.

Fluconazole is the most easily accessible effective antifungal drug against oral candida and therefore our choice. Seven out of the eight patients who received fluconazole received it upfront for obvious oral candidiasis. One patient received it prophylactically as a result of persistent fever beyond day five. A multicenter randomized trial by Winston et al $^{17}$ and a meta-analysis of sixteen randomized trials published by
Kanda et $a l^{18}$ have indicated that fluconazole may not be the best choice for fungal infections in febrile neutropenic patients as it fails to eradicate Aspergillus and other fungal types. Amphotericin B and Itraconazole are better choices.

Eleven $(55 \%)$ patients received received combination of ceftriaxone and gentamicin mostly due to cost constraints. However, several studies from developing countries like ours support the use of this combination in febrile neutropenia: Au et al, ${ }^{19}$ Ariffin et $a l^{20}$ and Pession et $a l^{21}$ have demonstrated the cost effectiveness of ceftriaxone/amikacin or gentamicin as empiric therapy. Only one patient who received this combination as initial therapy required antibiotic change.

Five $(84 \%)$ out of six patients who received amoxicillin/ clavanulic acid with levofloxacin or ciprofloxacin as empiric therapy required a change in antibiotic. This may indicate that in spite of its low cost, this is not a good combination for moderate to high risk patients as per this group.

\section{Use of Granulocyte Colony Stimulating Factors}

The use of GCSF was limited due to high cost. It was used upfront in one patient. Seven other patients received it for an average of three days to improve recovery rate of neutrophil and shorten duration of stay after five days of prolonged neutropenia. The American Cancer Society recommendations $2006^{22}$ and a Cochrane analysis ${ }^{23}$ on the subject of GCSF concluded that its use has no impact on mortality from this fatal condition but may in fact reduce morbidity and duration of hospital stay. The mean duration of fever was 4.5 days. A study from the Netherlands ${ }^{24}$, a high resource country reported their average as seven days.

Eighteen (90\%) recovered fully from febrile neutropenia.

Our ten percent mortality rate is comparable to worldwide average mortality rate for solid tumours of eight to ten percent. ${ }^{25,26}$

We must be reminded that one in ten patients on anticancer medication will develop febrile neutropenia irrespective 
of tumour type ${ }^{27}$ and therefore must endeavour to protect our patients from this fatal condition whilst optimising benefit from chemotherapy. This may be difficult for poorer countries, as presently GCSF is the only means of preventing dose reductions by protecting the white cell count. ${ }^{28}$

\section{Use of Prophylactic Antibiotics}

Two important studies published in $2005^{29,30}$ involving a total of 2,300 patients have suggested the use of prophylactic antibiotics in severely neutropenic patients to prevent infection.

Even though the incidence and risk of mortality were influentially reduced, prophylactic antibiotic use induced resistant patterns which has public health implications and future use of these drugs if patient develops fever. ${ }^{31}$ Gafter-Gvilli et al also published results of a meta-analysis of fifty-six trials on the effect of antibiotic resistance in quinolone prophylaxis of neutropenic patients and concluded that the risk does not outweigh the gain. ${ }^{32}$ From our study with limited patients, our results do not support the use of prophylactic amoxillicin/clavulinic acid on cephalosporin due to low fever recovery rate in the event of febrile neutropenia. A larger study is required to explore this further in our environment.

\section{Conclusion}

Febrile neutropenia can be managed in low resource countries with comparable outcomes as developed countries in spite of several limitations. A good history and physical examination are important components of management and impacts the choice of empiric antimicrobials. Aminoglycosides are an important component of empiric combination antibiotic treatment in our setting. In the near future we need to evaluate the economics of risk of death, cost of treatment and the cost effectiveness of prophylactic G-CSF for prevention.

\section{ACKNOWLEDGEMENT}

We would want to acknowledge $\mathrm{Mr}$. J. Hackman for his contribution to this paper.

\section{Funding}

There as no funding support for this retrospective study.

\section{Transparency Declarations Section}

There are no conflicts of interest with funding with either authors.

\section{REFERENCES}

1. Caggiano V, Weiss RV, Rickert TS, Linde-Zwirble WT. Incidence, cost and mortality of neutropenia hospitalisation associated with chemotherapy. Cancer 2005;103:1916-24.

2. Hsieh MM, Everhart JE, Byrd-Holt DD, Tisdale JF, Rodgers GP. Prevalence of neutropenia in U.S population: age, sex, smoking status and ethnic differences. Ann Intern Med. 2007; 146: 486-92.

3. M Ellis. Management of febrile neutropenia. Journal of Medical Sciences 2008; 1: 50-60.

4. Bodey GP, Buckley M, Sathe YS, Friereich EJ. Quantitative relationships between circulating leucocytes and infection in patients with acute leukemia. Ann Intern Med 1966; 64: 328-40.

5. Schimpff SC, Satterlee W, Young VM, Serpick A. Empiric therapy with carbenicillin and gentamicin for febrile patients with cancer and granulocytopenia. N Engl J Med 1971; 284: 1061.

6. Hughes, WT, Armstrong D, Bodey GP, Bow EJ, Brown AE, Calandra T et al. Guidelines for use of antimicrobials in neutropenic patients with cancer. Clin Infectious Disease 2002; 34: 730-51.

7. Vidal L, Paul M, Ben Dor Itisk, Karla Soares-Weiser, Leonard Leibovici. Oral versus intravenous antibiotic treatment for febrile neutropenia in cancer patients. A systematic review and metaanalysis of randomized trials. Journal of Antimicrobial Chemotherapy 2004; 54: 29-37.

8. Klastersky J, Paesmans M, Rubenstein EB, Boyer M, Elting L, Feld R et al. The Multinational Association for Supportive Care in Cancer risk index: A Multinational scoring system for identifying low-risk febrile neutropenic patients. J Clin Oncol. 2000; 18: 17689.

9. Bonadonna G, Valagussa R, Moliterni A, Zambetti M, Brambilla C. Adjuvant cyclophosphomide, methotrexate and fluorouracil in node-positive breast cancer-The results of 20 years of follow up. N Engl J Med 1995; 332: 901-906.
10. Bosly A, Bron D, Van Hoof R, Bock, R. Berneman, Z. Ferrant A et al. Achievement of optimal average relative dose intensity and correlation with survival in diffuse large B cell lymphoma patients treated with CHOP. Ann Hematology 2008; 87: 277-283.

11. Smith GF, Tooten TR. Primary care of the patient with cancer. American Family Physician 2007; 75: 1207-14.

12. Curtin JP, Hoskins WJ, Rubin SC, Jones WB, Hakes TB, Markman MM et al. Chemotherapy induced neutropenia and fever in patients receiving cisplatin based chemotherapy for ovarian malignancy. Gynaecol Oncol 1991; 40: 17-20.

13. Lalami Y, Paesmans M, Muanza F, Plehiers B, Debreucq L, Georgala A et al. Can we predict duration of chemotherapy-induced neutropenia in febrile neutropenic patients, focusing on regimen specific risk factors? A retrospective analysis. Annals of Oncology 2006;17: 507-514.

14. Crawford J, Dale DC, Kuderer NM, Nicole M, Culakova E, Poniewierski MS et al. Risk and timing of neutropenic event in patients receiving chemotherapy: The results of a prospective nationwide study of oncology practice. J Natl Comp Cancer Network 2008; 6: 109-118.

15. Wiplinghoff H, Siefert H, Wenzel RP. Current trends in the epidemiology of nosocomial blood stream infections in patients with hematological and solid neoplasms in the United States. Clin Infectious Dis 2003; 36: 113-120.

16. Commeta A, Calandra T, Gaya H, Zinner $\mathrm{SH}$, de Bock R, Del Favero A et al. Monotherapy with meronem versus combination therapy Ceftazidime plus amikacin as empiric therapy for fever in granulocytic patients with cancer. Antimicrobial Agents Chemother 1996; 40: 1108-15.

17. Winston DJ, Hathorn JW, Schuster MG, Schiller GJ, Territo MC. A multicenter randomized trial of fluconazole versus amphotericin B for empiric antifungal therapy for febrile neutropenic patients with cancer. $A m J$ Med 2000; 108: 282-9.

18. Kanda Y, Yamoto R, Chizuka A. Prophylactic action of oral fluconazole against fungal infections in neutropenic patients. A meta-analysis of sixteen randomized control trials. Cancer 2004; 89: 1611-25.

19. Au E, Ang PT. Management of chemotherapy induced neutropenic sepsis. Combination and aminoglycoside. Ann Acad Med Singapore 1993; 22: 319-22. 
20. Arriffin H, Arasu A, Mahfuzah M, Arrifin WA, Chan LL, Lin HP et al. Single daily ceftriaxone plus amikacin versus trice daily ceftazidime plus amikacin as empirical treatment of febrile neutropenia in children with cancer. J Pediatr Child Health 2001; 37: 38-43.

21. Pession A, Prete A, Paolucci G. Cost effectiveness of ceftriaxone and amikacin as single dose for the empirical management of febrile granulopenic children with cancer. Chemotherapy 1997; 43: 358-60.

22. Smith TJ, Khatcheressian J, Lyman GH, Ozer H, Armitage JO, Balducci L et al. Update of recommendations for the use of white cell growth factors: an evidence based clinical practice guideline. J Clin Onc 2006; 24: 3187-3205.

23. Clark OAC, Lyman G, Castro AA, Luciana GO, Djulbegovic CB. Colony stimulating factors for chemotherapy induced febrile neutropenia. Cochrane Database of Systematic reviews. 2003. Issue 3.
24. Claudi Oude Nighus, Williem A Kamps, Simon MG, Daenen AJ, Gietema WTA, van der Graaf HJM et al. Feasibility of withholding antibiotics in selected febrile neutropenic cancer patients. Journal of Clinical Oncology 2005; 23: 7437-7444.

25. Crawford J, Dale DC, Lyman GH. Chemotherapy induced neutropenia. Risk, consequences and new directions for its management. Cancer 2004; 100: 228-237.

26. Kuderer NM, Dale DC, Crawford J, Cosler LE, Lyman GH. Mortality, morbidity and cost associated with febrile neutropenia in Adult cancer patients. Cancer 2006; 106: 2258-66.

27. Lyman GH, Kuderer NM. The economics of the colony stimulating factors in the prevention and treatment of febrile neutropenia. Crit Rev Oncology Hematol 2004; 50: 129-46.

28. Aapro MS, Cameron DA, Pettengell R, Bohlius J, Crawford J, Ellis M. EORTC guidelines for use of granulocyte- colony stimulating factor to reduce the incidence of chemotherapy induced neutropenia in adult patients with lymphoma and solid tumours. Eur $J$ Cancer 2006; 42: 2433-53.

29. Cullen M, Steven MD, Billingham L, Gaunt C, Hastings M, Simmonds P et al. Antibacterial prophylaxis after chemotherapy for solid tumours and lymphomas. $N$ Eng J Med 2005; 353: 988-98.

30. Bucaneve G, Micozzi A, Menichetti F, Martino P, Dionisi S, Martinelli G et al. Levofloxacin to prevent bacterial infection in patients with cancer and neutropenia. N Eng J Med 2005; 353: 977-87.

31. Baden LR. Prophylactic antimicrobial agents and the importance of fitness. $N$ Eng J Med 2005; 353: 1052-17.

32. Anat Gafter-Gvilli, Mical Paul, Abigail Fraser, Leonard Leibovici. Effect of quinolone prophylaxis in afebrile neutropenic patients on microbial resistance: a systematic review and meta-analysis. J Antimicrob Chemother 2007; 59: 5-22. 